Article publié par le Laboratoire de Construction en Béton de l'EPFL

Paper published by the Structural Concrete Laboratory of EPFL

\begin{tabular}{|l|l|}
\hline Title: & $\begin{array}{l}\text { Assessing the compressive strength of concrete under sustained actions: from } \\
\text { refined models to simple design expressions }\end{array}$ \\
\hline Authors: & Tasevski D., Fernández Ruiz M., Muttoni A. \\
\hline Published in: & $\begin{array}{l}\text { Structural Concrete } \\
\text { https://onlinelibrary.wiley.com/doi/abs/10.1002/suco.201800303 }\end{array}$ \\
\hline DOI & $10.1002 /$ suco.201800303 \\
\hline $\begin{array}{l}\text { Volume: } \\
\text { Pages: }\end{array}$ & $\begin{array}{l}20 \\
971-985\end{array}$ \\
\hline Year of publication: & 2019 \\
\hline $\begin{array}{l}\text { Type of publication: } \\
\text { EPFL InfoScience link: }\end{array}$ & $\begin{array}{l}\text { Peer reviewed journal article } \\
\text { https://infoscience.epfl.ch/record/266057 }\end{array}$ \\
\hline
\end{tabular}

Please quote as:

Tasevski D., Fernández Ruiz M., Muttoni A., Assessing the compressive strength of concrete under sustained actions: from refined models to simple design expressions, Structural Concrete, 20, 2019, 971-985. 


\title{
Assessing the compressive strength of concrete under sustained actions: From refined models to simple design expressions
}

\author{
Darko Tasevski @ I Miguel Fernández Ruiz @ I Aurelio Muttoni
}

École Polytechnique Fédérale de Lausanne, School of Architecture, Civil and Environmental

Engineering, Lausanne, Switzerland

\section{Correspondence}

Darko Tasevski, School of Architecture, Civil and Environmental Engineering, École Polytechnique

Fédérale de Lausanne, Station 18, CH-1015

Lausanne, Switzerland.

Email: darko.tasevski@epfl.ch

Funding information

Swiss Federal Roads Office (FEDRO), Grant/

Award Number: AGB-2013-001
The detrimental influence of high levels of sustained load on the compressive strength of concrete has been acknowledged and investigated since the 1950s. Despite the potential significance of this phenomenon in many situations, current design codes still provide limited guidance on how to account for this effect at ultimate limit state. In addition, the practical case of a significant permanent stress followed by stress increases due to variable loads is not addressed in most codes of practice. The aim of this paper is to present a general but simple design approach to account for the influence of sustained loading on the uniaxial behavior of concrete in compression, both in terms of its strength and deformation capacity. This approach is based on a previously developed mechanical model accounting for nonlinear creep and material damage development on the long-term response of concrete. On that basis, a design approach is formulated in a simple code-like manner and used to investigate several practical design situations involving both sustained and variable actions. This approach is shown to be consistent and applicable to any general loading pattern, accurately reproducing the results of the general mechanical model and of available experimental results.

\section{KEYWORDS}

deformation capacity, inelastic strain, internal redistribution, loading pattern, long-term strength, nonlinear creep, strain rate, sustained load

\section{1 | INTRODUCTION}

As already well-established since the early developments of concrete, the compressive strength increases with time due to the continued cement hydration ${ }^{1}$ (see red curve in Figure 1a). For this reason, already the first standards for reinforced concrete defined a concrete age $\left(t_{\text {ref }}\right)$ to characterize the compressive strength of concrete and its associated mechanical properties (for instance 28 days according to the Swiss Code of $1903,{ }^{2} 90$ days according to the French Code of 1906 and 42 days according to the Austrian Code of 1907, refer to Mörsch $^{3}$ ). The reference time was in these

Discussion on this paper must be submitted within two months of the print publication. The discussion will then be published in print, along with the authors' closure, if any, approximately nine months after the print publication. codes in accordance to the rules related to the age at which removal of the scaffolding was allowed (which were usually lower than $t_{r e f}$, see for instance the Swiss Code of $1903^{2}$ ). This approach already implicitly considered that additional permanent loads and variable actions are relevant for the structural performance in addition to self-weight, and that they are usually applied at a time larger than $t_{r e f}$ (see blue curve in Figure 1a).

When assessing the structural performance at ultimate limit state, the uncertainties related to actions (higher stresses than expected) and the uncertainties related to the concrete strength (including the difference between the strength of the specimens for concrete testing and the local in-situ strength) have to be accounted for. This can be done by considering characteristic values for the actions and material properties 

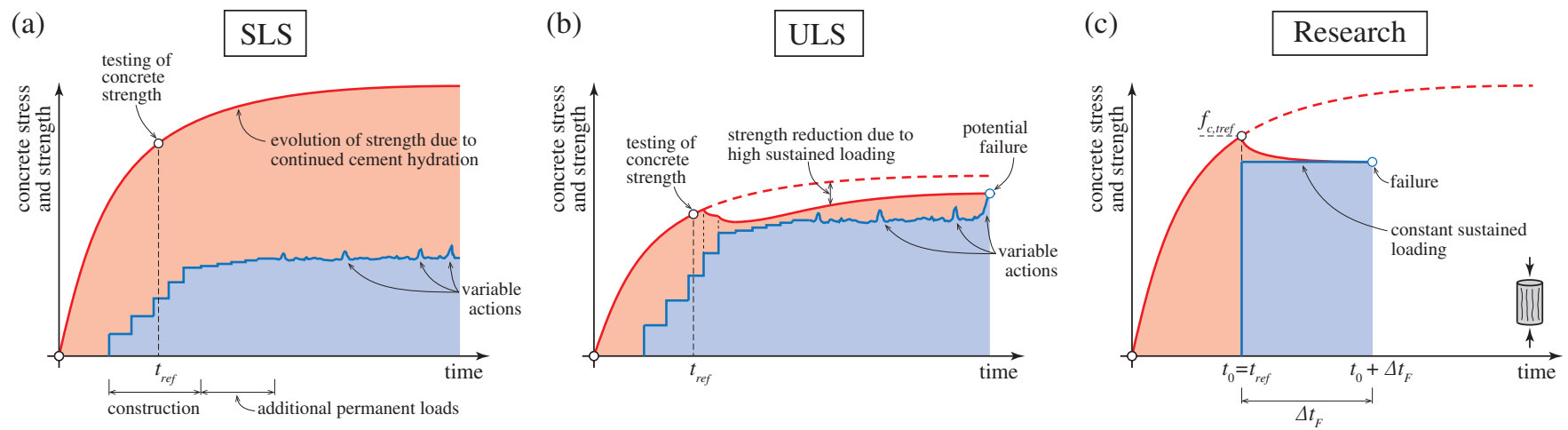

FIGURE 1 Stress (blue) and strength (red) evolutions in time: (a) characteristic values for typical structures; (b) design values at Ultimate Limit State (ULS); and (c) typical tests investigating the effect of sustained load

and by applying pertinent partial safety factors (as performed in Figure 1b with respect to Figure 1a). This means that the verification is performed using design values for the internal actions and resistances. It can be noted that, in this frame of ultimate limit state analysis (which is a potential real situation, although with a very small probability of occurrence) the acting stresses may be relatively high compared to the material resistance, ${ }^{4}$ which may be detrimental for the material strength. ${ }^{5}$

This phenomenon (see Figure 1b) was already observed in the 1950s by the pioneer works of Shank ${ }^{6}$ and later investigated in detail by Rüsch. ${ }^{7-9}$ According to Rüsch, ${ }^{8}$ when a high level of stress is applied to the concrete at a certain age $\left(t_{0}\right)$, the strength of the material does not necessarily increase with time (as for unloaded specimens due to the continued cement hydration), but it may reduce. This occurs normally for stress levels above approximately $75-80 \%$ of the strength of the material at the time of loading $\left(f_{c, t 0}\right.$, tested under standard conditions leading to failure in about 1-2 min according for instance to ISO $1920-4: 2005^{10}$ ). This fact is sketched in Figure 1c for a concrete specimen subjected to a constant level of high stress (but below the resistance of the concrete at the time of loading, $f_{c, t 0}$ ), showing that failure occurs after some time of application of the action. According to these observations, Rüsch ${ }^{8}$ established the concept of sustained load strength, that he defined as the maximum stress level at which concrete can be permanently loaded without failure.

For the case of actual structures, the detrimental influence of high levels of sustained load is only notorious after a significant fraction of the permanent load has been applied to the structure. This can be seen in Figure 1b, by the decay in the red curve (material resistance) for high levels of permanent load. Thereafter, the strength may increase again due to the continued cement hydration, but in any case the strength is reduced with respect to that of an unloaded material (dashed red curve in Figure 1b). Failure will eventually occur when the action equals the resistance, which may take place at different moments depending on the acting variable actions and material decay on the strength (as already observed by Rüsch ${ }^{8}$ and others, ${ }^{11-13}$ see Figure 1b).
Due to its practical relevance, the topic of the long-term strength of concrete structures has attracted many research efforts after the works of Rüsch, with a number of investigations conducted both for normal strength concrete $^{11,13-22}$ and high-strength concrete. ${ }^{22-27}$ The same phenomenon has been also investigated for the tensile and flexural behavior under sustained load (see for instance References 28-30). Within this frame, most experimental evidence with respect to the effect of sustained loading on the compressive strength has been obtained by considering a constant stress level applied to the member (refer to the load pattern shown in Figure 1c). However, some experimental programs and researches have also reported this phenomenon for low loading rates. ${ }^{14,31,32}$ Several authors have also investigated the origin of the phenomenon, relating the delayed failure of concrete to microcracking and to material damage development and progression. ${ }^{14,19,33,34}$ According to these research works, if the level of sustained stress is higher than the threshold at which microcrack propagation is likely to occur $\left(\sigma_{c} f f_{c}>0.4\right.$, typically associated to the development of nonlinear creep strains), delayed damage may develop in the material. At elevated sustained stress levels $\left(\sigma_{c} / f_{c}>0.75\right.$, corresponding to Rüsch's sustained load strength), a significant amount of delayed damage may develop, yielding to unstable crack propagation over time and potentially to material failure.

For moderate levels of permanent load ( $\sigma$ between $\sim 0.4 \cdot f_{c}$ and 0.6 $f_{c}$ ) applied to the material, a small beneficial influence of sustained levels of stress has been observed on the material strength. ${ }^{19}$ This fact, confirmed experimentally, ${ }^{35}$ has been attributed to the beneficial internal stress redistributions occurring in the material ${ }^{19}$ (reducing stress concentrations; alternative explanations of this phenomenon can be consulted elsewhere ${ }^{36}$ ), but is usually neglected in practice.

With respect to codes, the approach for the design of new structures usually considers that the detrimental effect of sustained loads on the concrete strength can be compensated by the increase of strength due to continued cement hydration after the reference time $t_{\text {ref }}$. This is for instance the approach followed by MC2010 ${ }^{37}$ and EN 1992-1-1:2004 ${ }^{38}$ when the reference strength is considered at a time $t_{\text {ref }}$ equal 
to 28 days. However, when the reference time for evaluation of the compressive strength is higher $\left(t_{r e f}>28\right.$ days), the uniaxial compressive strength has to be reduced accordingly to account for the effects of sustained loading (refer for instance to coefficient $k_{t}$ in $\mathrm{EN} 1992-1-1: 2004,{ }^{38}$ recommended to be 0.85 in $\S 3.1 .2(4)$ ). This is a typical situation for the assessment of existing structures, where the concrete strength can be updated after long periods of service of the structure and almost no strength increase due to cement hydration can be expected anymore (this also presumes that concrete has suffered no degradation processes such as alkali-aggregate reaction, sulfate attack or freezethaw cycles). However, when a general loading case is considered (refer for instance to Figure 1b) there is usually little or no guidance on how to determine in a simple and consistent manner the uniaxial compressive strength of concrete.

In this context, the aim of this paper is to provide a simple analytical approach to evaluate the compressive strength of concrete when subjected to long-term actions and accounting for potentially high levels of stress. The topic is analyzed by using the theoretical frame of Tasevski et al., ${ }^{13}$ which provides a model to assess the material damage and its influence both in terms of strength and deformation capacity. The model is consistently verified with test results considering different loading patterns (sustained stress, stress rates and strain rates) and formulated in a design-friendly manner. On that basis, several practical design situations are analyzed, deriving a number of practical recommendations.

\section{I CONCRETE STRENGTH IN CASE OF CONSTANT SUSTAINED LOADING}

A number of approaches on the modeling of nonlinear creep and associated damage as well as for prediction of delayed failure of concrete can be found in literature. Many of these approaches are based on material damage development ${ }^{13,14,31,39-43}$ and others are based on fracture mechanics. ${ }^{19,44-47}$ Within this work, the approach of Tasevski et al. ${ }^{13}$ will be followed. This approach

(a)

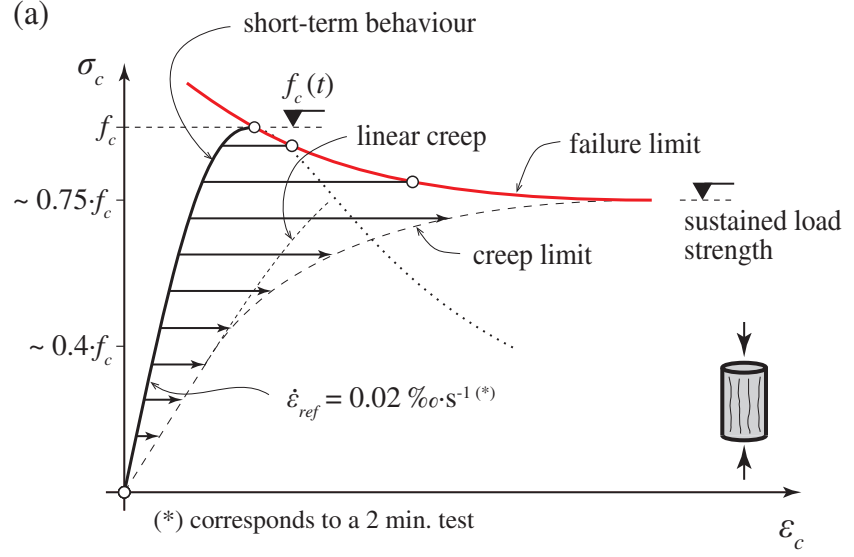

is based on the hypothesis of affinity between linear and nonlinear creep strains (proposed by Fernández Ruiz et al. ${ }^{14}$ ) and accounts for material damage development associated to nonlinear creep. This chapter gives a short review of this approach.

\section{1 | Nonlinear creep strains}

If concrete is subjected to a compressive stress lower than $\sim 0.4 \cdot f_{c}$, the correlation between the delayed creep strain and the instantaneous strain is almost linear (Figure 2a) and thus governed by a linear creep phenomenon without development of any significant material damage. At higher stress levels $\left(\sigma_{c} / f_{c}>0.4\right)$, the linear correlation between the delayed creep strain and the instantaneous strain is lost and additional nonlinear creep strains develop. ${ }^{13}$ This loss of linear correlation is due to the damage process in the material associated to concrete microcracking.

According to several authors, ${ }^{33,42,44}$ the development of inelastic strains associated to material damage can be separated into three phases (Figure 2b). In the primary creep phase (immediately after load application), the strains develop at a high-initial rate and stabilize with time. In the following (secondary creep) phase, the rate is fairly constant. At high-load levels, the microcrack propagation becomes unstable and leads to failure of the specimen (see Figure 2), corresponding to the tertiary creep phase. This latter phase is characterized by an increasing rate of strains, resulting in an uncontrolled process of crack coalescence.

\section{2 | Failure criterion}

Following the approach of Fernández Ruiz et al., ${ }^{14}$ the inelastic strain capacity $\varepsilon_{c c, i n, a v}$ for a given stress level defined as the difference between the instantaneous postand pre-peak strains for that level of stress (Figure 3a) can be assumed as the governing parameter for the failure criterion. This value can be directly calculated by using the monotonic stress-strain curve of concrete in compression, as

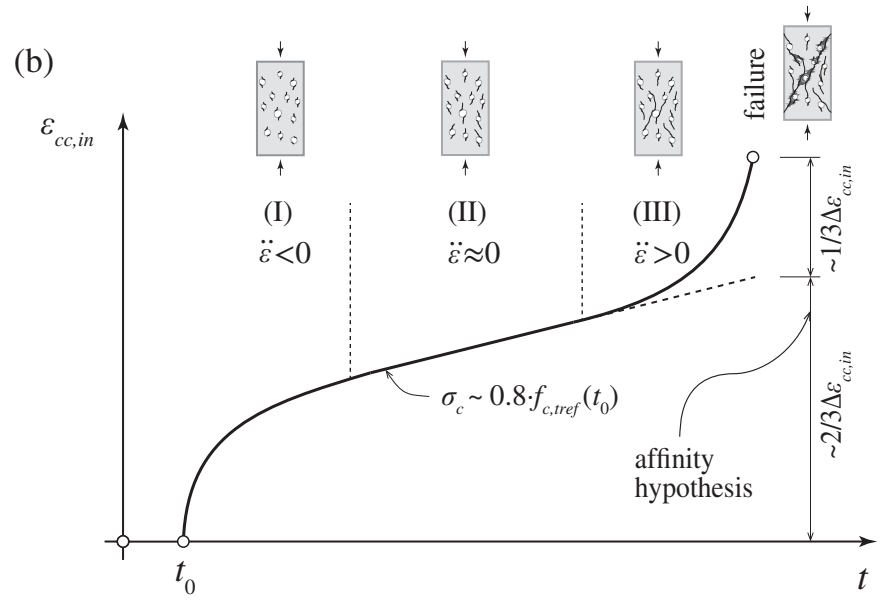

FIGURE 2 Uniaxial compressive behavior of concrete: (a) short- and long-term stress-strain response, adapted from Rüsch ${ }^{8}$; (b) stages of creep: Primary, secondary and tertiary; definition of the affinity hypothesis 
further verified experimentally by Tasevski et al. ${ }^{13}$ The monotonic response is considered to be obtained at a reference strain rate of $\dot{\varepsilon}=0.02 \% \circ \cdot \mathrm{s}^{-1}(\sim 2$ min to reach the maximum strength). Failure is considered to occur when the total inelastic strain developed by the material (accounting for secondary and tertiary creep strains) equals the inelastic deformation capacity (see Figure 3b).

Similar approaches by other authors have been reported, where the monotonic stress-strain curve is used as a failure criterion for fatigue life ${ }^{5,48,49}$ Details on the development of inelastic strain related to material damage and on the calculation of failure can be found in Tasevski et al. ${ }^{13}$ and are summarized in the following section.

\section{3 | Development of inelastic strain by concrete at high stress levels}

According to Tasevski et al., ${ }^{13}$ the strains developed for a concrete loaded at time $t_{0}$ can be described in a general manner by the following expression:

$$
\varepsilon_{c}\left(t, \frac{\sigma_{c}}{f_{c}}\right)=\varepsilon_{c 0}\left(t_{0}, \frac{\sigma_{c}}{f_{c}}\right)+\Delta \varepsilon_{c s}\left(t, t_{0}\right)+\Delta \varepsilon_{c c}\left(t, t_{0}, \frac{\sigma_{c}}{f_{c}}\right),
$$

where the first term on the right side of the equation $\left(\varepsilon_{c 0}\left(t_{0}, \frac{\sigma_{c}}{f_{c}}\right)\right)$ corresponds to the instantaneous prepeak strain (including elastic and inelastic components, refer to the short-term behavior in Figure 2a), the second $\left(\Delta \varepsilon_{c s}\left(t, t_{0}\right)\right)$ to the shrinkage strains (assumed not to be associated to any material damage) and the third $\left(\Delta \varepsilon_{c c}\left(t, t_{0}, \frac{\sigma_{c}}{f_{c}}\right)\right)$ to the creep strains. ${ }^{13}$

The creep strains can be divided into primary, secondary and tertiary creep in the following manner:

$$
\begin{aligned}
\varepsilon_{c c}\left(t, t_{0}, \frac{\sigma_{c}}{f_{c}}\right)= & \varepsilon_{c c, 1}\left(t, t_{0}\right)+\varepsilon_{c c, 2}\left(t, t_{0}, \frac{\sigma_{c}}{f_{c}}\right) \\
& +\varepsilon_{c c, 3}\left(t, t_{0}, \frac{\sigma_{c}}{f_{c}}, \frac{\varepsilon_{i n}}{\varepsilon_{i n, a v}}\right),
\end{aligned}
$$

(a)

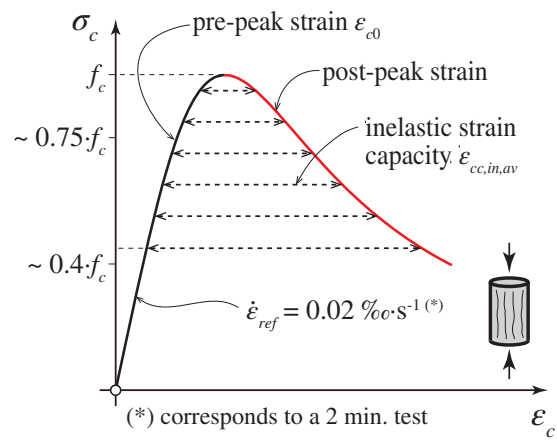

where the primary creep strains are calculated by means of the linear creep coefficient (and are not associated to material damage):

$$
\varepsilon_{c c, 1}\left(t, t_{0}\right)=\varphi_{\text {lin }} \cdot \varepsilon_{c 0}
$$

The secondary creep strains (due to micro-cracking development and thus associated to material damage) are evaluated as ${ }^{14}$ :

$$
\varepsilon_{c c, 2}\left(t, t_{0}, \frac{\sigma_{c}}{f_{c}}\right)=(\eta-1) \cdot \varepsilon_{c c, 1}\left(t, t_{0}\right),
$$

where the coefficient $\eta$ is expressed as follows ${ }^{13,14}$ :

$$
\eta\left(\frac{\sigma_{c}}{f_{c}}, t, t_{0}\right)=\left(1+2 \cdot \eta_{\tau}\left(t, t_{0}\right)\left(\frac{\sigma_{c}}{f_{c}(t)}\right)^{4}\right),
$$

and coefficient $\eta_{\tau}$ takes into account the development of the nonlinear creep strains with time ${ }^{13}$ :

$$
\eta_{\tau}\left(t, t_{0}\right)=\left(1-\log \left(\frac{t-t_{0}}{t_{m}+t-t_{0}}\right)\right)^{n},
$$

where constant values $t_{m}=100$ days and $n=0.75$ can be generally assumed. ${ }^{13}$ It can be noted that when $t \rightarrow \infty$, then $\eta_{\tau} \rightarrow 1$ and consequently Equation (6) takes the form originally suggested by Fernández Ruiz et al. ${ }^{14}$ for nonlinear creep strains after a long time.

The development of tertiary creep strains (associated to micro-crack coalescence and thus also to material damage) can be evaluated by taking into accounting the ratio of developed-to-available inelastic strains $\left(\varepsilon_{c c, i n} / \varepsilon_{c c, i n, a v}\right)$ and the level of stress, calculated by means of the following equation ${ }^{13}$.

$$
\begin{gathered}
\varepsilon_{c c, 3}\left(t, t_{0}, \frac{\sigma_{c}}{f_{c}}, \frac{\varepsilon_{c c, i n}}{\varepsilon_{c c, i n, a v}}\right)=\gamma\left(\frac{\sigma_{c}}{f_{c}}, \frac{\varepsilon_{c c, i n}}{\varepsilon_{c c, i n, a v}}\right) \\
\cdot \varepsilon_{c c, 2}\left(t, t_{0}, \frac{\sigma_{c}}{f_{c}}\right) .
\end{gathered}
$$

In the ratio $\varepsilon_{c c, i n} / \varepsilon_{c c, i n, a v}$, the term $\varepsilon_{c c, i n, a v}$ corresponds to the total available inelastic strain and is characterized by the short-term monotonic response of concrete (Figure 3a). The

(b)

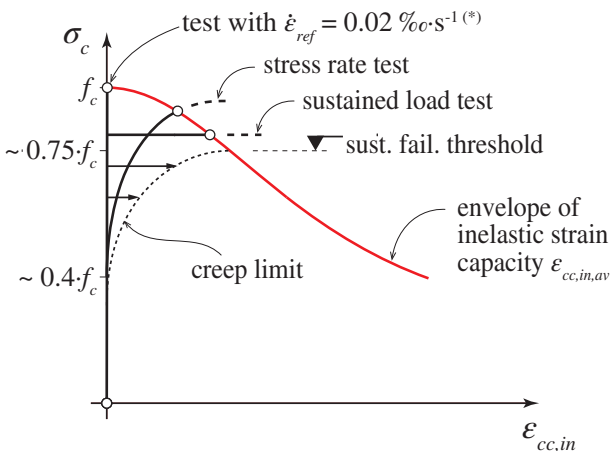

FIGURE 3 Inelastic strain capacity $\varepsilon_{c c, i n, a v}$ according to Fernández Ruiz et al. ${ }^{14}$ : (a) definition of $\varepsilon_{c c, i n, a v}$ as the difference between post- and pre-peak strains of the monotonic curve; (b) definition of failure as intersection of the stress-inelastic strain curve and the failure envelope of $\varepsilon_{c c, i n, a v}$ (Tasevski et al. ${ }^{13}$ ) 
term $\varepsilon_{c c, \text { in }}$ corresponds to the developed nonlinear creep strain (total strain minus shrinkage, instantaneous and linear creep strains).

For low values of the ratio $\varepsilon_{c c, i n} / \varepsilon_{c c, i n, a v}$, tertiary creep strains have a negligible contribution, whereas they increase at a growing rate when failure approaches. As suggested by Tasevski et al., ${ }^{13}$ the parameter $\gamma$ can be calculated with help of the following expression:

$$
\gamma=\frac{1}{2} \cdot\left(\frac{\varepsilon_{c c, i n}}{\varepsilon_{c c, i n, a v}(t)}\right)^{\alpha} \text { for } \sigma_{c} / f_{c}(t) \geq 0.75 .
$$

According to this assumption, $\gamma$ is zero for stress levels below the threshold of possible tertiary creep development $\left(\sigma_{c} l f_{c}=0.75\right)$. The shape of the tertiary creep curve is governed by the parameter $\alpha$, which can be considered equal to 4 , based on the analysis of experimental results by Tasevski et al. ${ }^{13}$ At failure, $\varepsilon_{c c, i n}=\varepsilon_{c c, i n, a v}$ which results $\varepsilon_{c c, 3}=1 / 2 \varepsilon_{c c, 2}$. This formula is in addition consistent with the affinity hypothesis originally formulated by Fernández Ruiz et al. ${ }^{14}$ that considers $\varepsilon_{c c, 2}=2 / 3 \varepsilon_{c c, i n, a v}$ and $\varepsilon_{c c, 3}=1 / 3 \varepsilon_{c c, i n, a v}$ (Figure 2b).

A significant advantage of the presented model is the fact that it is strain-based and allows thus tracking the amount of material damage for any loading history, and to calculate both the strength and deformation capacity of concrete for any potential loading pattern.

\section{4 | Comparison of the developed model to the fib MC2010 approach and proposal of an analytical expression}

According to $f i b \mathrm{MC} 2010^{37}$ (Equation (5.1-53)), the compressive concrete strength in case of a constant sustained loading starting at time $t_{0}$ and for a duration $\Delta t_{F}$ can be expressed by (Equation (5.1-53) of fib MC2010, ${ }^{37}$ notation adapted consistently to the one of this paper):

$$
f_{c}\left(t_{0}+\Delta t_{F}\right)=f_{c, 28} \cdot \beta_{c c}\left(t_{0}+\Delta t_{F}\right) \cdot \beta_{c, s u s}\left(\Delta t_{F}\right) .
$$

In this expression, the influence of two effects is considered: the increase of strength due to continued cement hydration $\left(\beta_{c c}\left(t_{0}+\Delta t_{F}\right)\right)$ which depends on the age at failure $t_{0}+\Delta t_{F}$ and the strength reduction due to sustained loading $\left(\beta_{c, \text { sus }}\left(\Delta t_{F}\right)\right)$ which depends on the load duration $\Delta t_{F}$. The parameter $\beta_{c c}\left(t_{0}+\Delta t_{F}\right)$ can be calculated for $t_{r e f}=28$ days with Equation (5.1-51) of fib MC2010 37 (notation adapted consistently to the one of this paper):

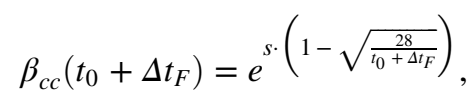

where $s$ is a coefficient that depends on the cement type. For $t_{\text {ref }}$ different to 28 days, Equation (10) has to be replaced by:

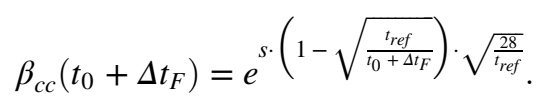

With respect to the parameter $\beta_{c, s u s}\left(\Delta t_{F}\right)$ in Equation (9), it accounts for the strength reduction due to sustained loading, and is evaluated by means of the following expression (Equation (5.1-54) from fib $\mathrm{MC} 2010,{ }^{37}$ notation adapted consistently to the one of this paper):

$$
\beta_{c, \text { sus }}\left(\Delta t_{F}\right)=0.96-0.12 \cdot\left(\ln \left(72 \cdot \Delta t_{F}\right)\right)^{1 / 4},
$$

where $\Delta t_{F}$ is measured in days. This expression has been obtained as a best fit of test results by the research group of Rüsch. ${ }^{8,9}$ It can be noted that, since the evaluation of the test data was made adding the initial loading time $(20 \mathrm{~min}$ for those tests) to the sustained loading duration, the expression is in principle only applicable for $\Delta t_{F}>0.015$ days (= $20 \mathrm{~min}$ ). In addition, the coefficient 0.96 in this expression covers the difference of a test loaded in $20 \mathrm{~min}$ and a standard test loaded in approximately 2 min. $^{50}$

Figure 4 presents a comparison of these expressions with the model described in the previous section and the test data gathered in Tasevski et al. ${ }^{13}$ collected from several research groups. ${ }^{6,9,17,22,26}$ The sustained loading duration has been corrected to account consistently for the duration of the initial loading phase. It can be seen in that figure that the fib MC2010 37 expressions (green lines in Figure 4a-c) provide a lower limit of the measured strength under sustained loading. Furthermore, the formula is only valid for times of application of the load larger than $20 \mathrm{~min}$, which makes the expression rather sensitive (strong drop on the strength after $20 \mathrm{~min}$ ) and limits its field of application. In addition, the coefficient $\beta_{c \text {,sus }}(\Delta t)$ according to MC2010 does not depend on the concrete age at loading $\left(t_{0}\right)$, but only on the time duration for which the load is applied $(\Delta t)$. However, according to the test results and the theoretical model, ${ }^{13}$ the age of concrete at loading is a significant parameter.

Figure 4 also plots the results of the model by Tasevski et al. ${ }^{13}$ (black solid curves in Figure 4). This approach yields to a smooth and gradual reduction of the strength with increasing times of application of the load.

Accounting for these facts, it is considered that current fib's MC2010 formula can be improved to yield to more consistent predictions of the behavior and to expand its range of validity to short-time applications of the load (lower than $20 \mathrm{~min}$ ). On the basis of the results presented in this paper and by analysis of the results, the following analytical expression is proposed for the phenomenon of strength reduction due to high levels of sustained loading:

$$
\beta_{c, \text { sus }}\left(t_{0}, \Delta t_{F}\right)=\lambda\left(t_{0}\right)+\frac{1-\lambda\left(t_{0}\right)}{\left(1+k_{2} \frac{\Delta t_{F}}{t_{0}}\right)^{1 / k_{1}}} .
$$

This expression is derived by fitting of the numerical predictions of the general model by Tasevski et al. ${ }^{13}$ with a simple analytical equation depending both on $t_{0}$ and $\Delta t_{F}$. It can be noted that Equation (13), differently to Equation (12), shows an explicit dependence on $t_{0}$ as: (1) the inelastic strain development is based on a creep model that depends on $t_{0}$ and $\Delta t_{F}$, and a monotonic response that depends on $t_{0}$; 
(a)

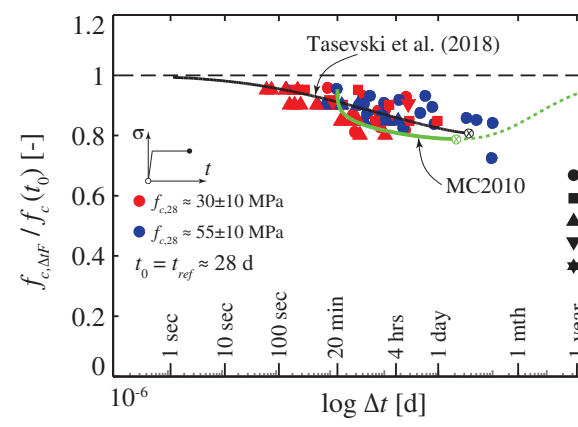

(d) (b)

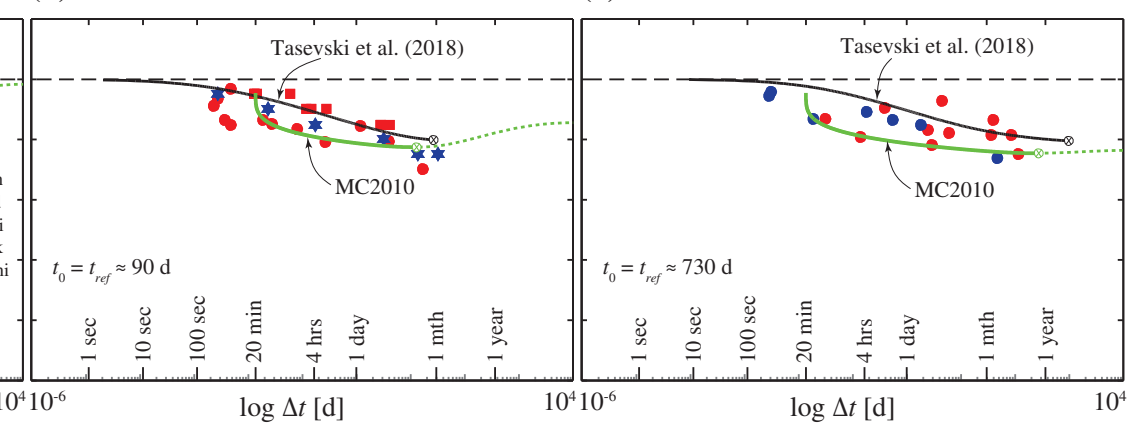

(e) (c)

(f)

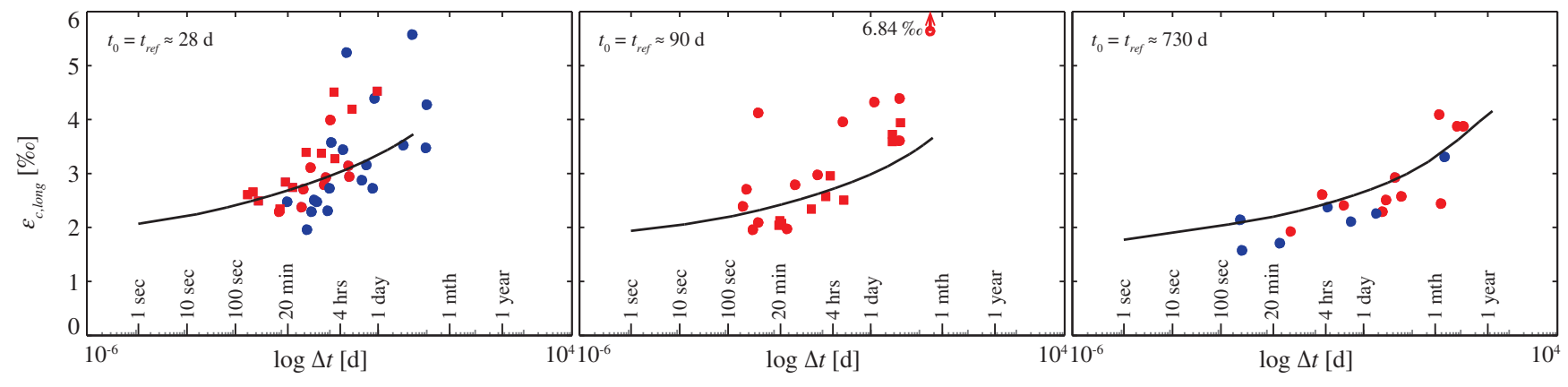

FIGURE 4 Comparison of experimental data points with the theoretical model ${ }^{13}$ (solid black lines, Tasevski et al. ${ }^{13}$ ) and fib MC2010 (Equation (12), solid green lines) for constant sustained stress $(s=0.25)$

(2) the failure envelope depends on the monotonic response which is calculated at $t_{0}+\Delta t_{F}$.

With respect to the parameters of Equation (13), the values $k_{1}=10 ; k_{2}=10^{4}$ and $\lambda\left(t_{0}\right)=0.64+0.01 \cdot \ln \left(t_{0}\right)$ (with $t_{0}$ in days) can be adopted yielding to overall accurate and consistent results. A comparison of the results of the model by Tasevski et al. ${ }^{13}$ and those of Equation (13) can be seen in Figure 5. A nice agreement is found, yielding in addition to a good approximation of the sustained load strength (values about $80 \%$ of the reference strength, indicated with a circle in Figure 4). It shall be noted that Figure 5 presents the failure of concrete under constant levels of stress. Cases where the material does not fail and additional loading can be applied will be discussed in Section 3 .

\section{5 | Deformation capacity and redistribution of internal forces}

Due to the fact that the development of nonlinear creep strains at high-stress levels may potentially lead to failure under sustained load, this phenomenon has traditionally been considered as a detrimental effect for concrete. With this respect, it shall nevertheless be noted that the development of nonlinear creep increases the deformations of the material at a non-proportional rate with respect to regions where linear creep governs. This phenomenon can be observed in Figure 2a, where the curve defining the creep limit (deformations of the material accounting for instantaneous and creep strains) loses the proportionality for stress levels above $40 \%$ of the (short-term) compressive strength of the material. Some test results as well as the predictions of the theoretical model by Tasevski et al. ${ }^{13}$ with respect to this phenomenon can also be seen in Figure $4 d-f$, where the deformation capacity at peak load is plotted as a function of the load duration.

As a consequence of this nonlinear response in terms of strains, redistributions of stresses can occur between regions deforming more (those subjected to high level of stresses and developing nonlinear creep strains) and those deforming less (those subjected to a linear creep response). This is a potentially beneficial influence of the development of nonlinear creep strains as it contributes reducing the stress level at the most stressed regions.

One clear example of this beneficial influence can be observed in the compression zone of members in bending, where the outermost compressed fibers reduce relatively

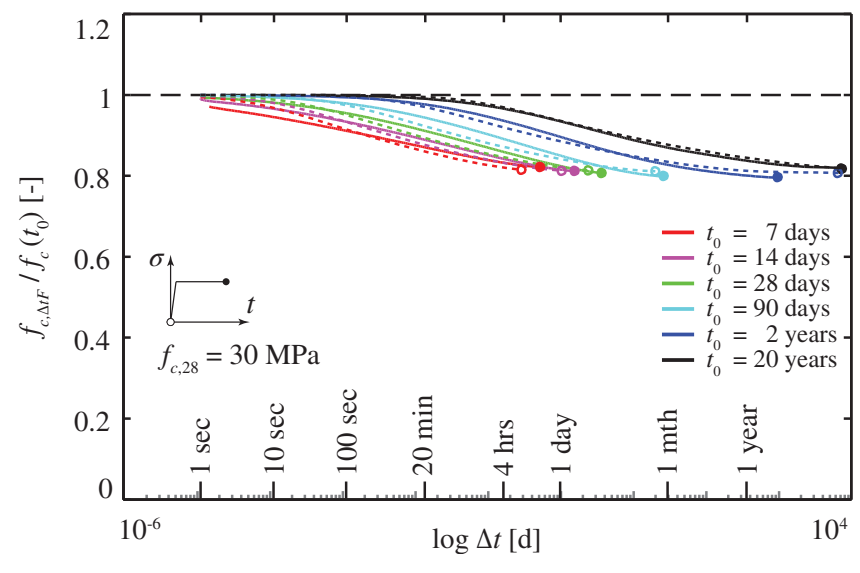

FIGURE 5 Comparison of theoretical model ${ }^{13}$ (solid lines) and analytical Equation (13) (dashed lines) for a constant sustained stress $\left(f_{c, 28}=30 \mathrm{MPa}\right.$ and $s=0.25)$ 
their stress due to nonlinear creep. As experimentally observed, ${ }^{8,51}$ this phenomenon justifies why adopting a parabolic/constant stress distribution in the compression zone due to bending is more realistic than adopting one based on the short-term material response and considering a linear profile of strains (see Figure 6). ${ }^{52}$

Another example where this phenomenon is significant refers to the response of reinforced concrete columns with limited second order effects. In these cases, governed by the compressive strength of concrete and by the presence of the longitudinal reinforcement steel, the additional deformation due to creep allows to increase the contribution of the compression reinforcement (which is potentially not yielded when concrete crushes under rapid loading conditions). Thus, while slow loading rates or sustained loading may be detrimental for the strength of columns with low longitudinal reinforcement ratios (low contribution of the reinforcement to the overall strength), it may be beneficial for columns with large reinforcement ratios (additional contribution of the reinforcement compensating for the decrease of the concrete contribution).

\section{I CONCRETE STRENGTH FOR DIFFERENT LOADING PATTERNS}

\section{1 | Introduction}

Despite the fact that most research on the topic of nonlinear creep behavior has been performed on specimens loaded under a constant sustained stress (Figure 1c), structures are

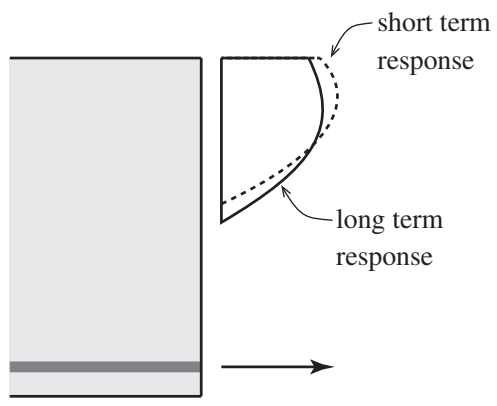

FIGURE 6 Compression zone of a member in bending with stress distribution under short-term and long-term loading seldom subjected to such type of loading. On the contrary, refer for instance Figure $1 \mathrm{~b}$, most structures are subjected to other loading patterns. With this respect, three loading patterns can be identified as particularly relevant for practice: approximately monotonic stress rates (Figure 7a, typically referring to the construction sequence); approximately monotonic stress rates after application of a first loading ramp (Figure $7 b$, typically referring to the application of dead loads after construction) or loading patterns with a rapid increase of load after a period of quasi-sustained loading (Figure 7c, typically referring to live loads in addition to permanent loads).

With reference to these patterns, design codes usually provide no general method to assess their structural response accounting for the progression of material damage with time. In addition, refined and general approaches (as the one of Tasevski et al. ${ }^{13}$ ) may be too complex for their application in practice. In the following, a simple methodology to calculate the response of a structure subjected to a general loading pattern will thus be presented. The approach is based on the Palmgren-Miner's rule, whose pertinence will be justified from a theoretical perspective and by comparison to test results. By making use of this tool, the various loading patterns relevant for practice shown in Figure 7 will be investigated (cases (a) and (b) in Section 3.3 and case (c) in Section 3.4).

\section{2 | The Palmgren-Miner's rule for linear damage accumulation}

The concept of linear damage theory was initially developed by Palmgren ${ }^{53}$ in 1924 and extended later by Miner ${ }^{54}$ in 1945 , being widely used thereafter to describe the fatigue life of engineering materials. ${ }^{55}$ Its main assumption considers that, when a material is subjected to a given stress amplitude, the damage accumulation is in linear correlation with the cycle ratio, that is, $D=\left(N / N_{F}\right)$, where $N$ refers to the number of cycles elapsed with a given stress amplitude and $N_{F}$ is the number of cycles that leads to failure for that stress amplitude. For variable amplitude fatigue loads, the total accumulation of damage $D$ would thus read:

$$
D=\sum_{i=1}^{n} \frac{N\left(\sigma_{i}\right)}{N_{F}\left(\sigma_{i}\right)},
$$

(a)

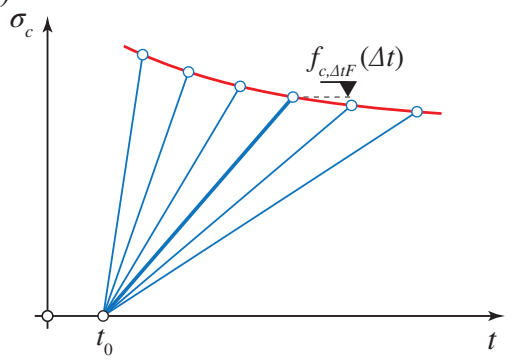

(b)

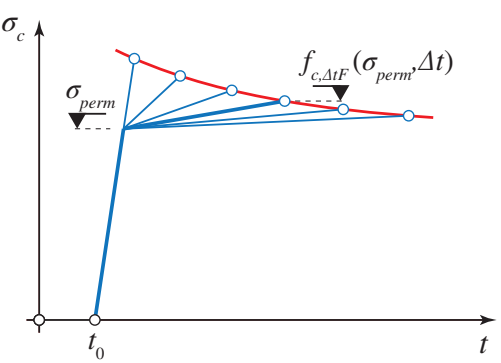

(c)

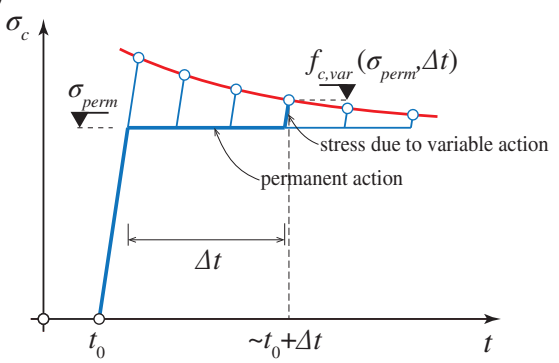

FIGURE 7 Investigated loading patterns: (a) stress rate without initial loading; (b) stress rate with initial rapid loading; and (c) additional loading after a period of sustained loading 
where $i$ is the index of the $i$-th amplitude (stress level $\sigma_{i}$ ), and the occurrence of failure would be given when $D=1$.

It is worth noting that Palmgren-Miner's formulation of damage does not account for the order in which the different stress levels are applied, which has been reported as a drawback of this rule. ${ }^{55}$ Also, there is actually no thoroughly mechanical justification grounding it. Another reported drawback is the linearity assumption of damage accumulation for all stress levels. ${ }^{56}$ Hence, some authors have contested the applicability of the Palmgren-Miner's rule for concrete, especially in the case of variable amplitude loadings and complex loading patterns. ${ }^{49,55,57-59}$ Despite these drawbacks, the Palmgren-Miner's rule has still been widely used due to its simplicity and reasonable fitting to test results, and is for instance acknowledged in fib Model Code $2010^{37}$ for detailed fatigue verifications.

With respect to the failure of concrete under variable sustained stress (low stress and strain rates), the PalmgrenMiner's rule can be applied by analogy to the case of fatigue life estimation under variable stress amplitudes, reading:

$$
D=\sum_{i=1}^{n} \frac{\Delta t\left(\sigma_{i}\right)}{\Delta t_{F}\left(\sigma_{i}\right)}(=1 \text { at failure }),
$$

where $\Delta t\left(\sigma_{i}\right)$ is the duration of the $i$-th level of sustained stress $\sigma_{i}$ and $\Delta t_{F}\left(\sigma_{i}\right)$ is the associated failure time for the same constant level of sustained stress (normally only occurring for stress levels above $\sigma_{c} l f_{c}=0.75$ ). The sum can also be written in an integral form in the following manner:

$$
\sum_{i=1}^{n} \frac{\Delta t\left(\sigma_{i}\right)}{\Delta t_{F}\left(\sigma_{i}\right)}=\int_{0}^{\Delta t} \frac{d t(\sigma)}{\Delta t_{F}(\sigma)}
$$

In the following sections, the Palmgren-Miner's rule will be used in combination with Equation (13) proposed in Section 2.4 for calculation of the time to failure $\left(\Delta t_{F}\right)$ for a given level of sustained load.

\section{3 | Application to a constant stress rate with and without initial stress level}

To apply the Palmgren-Miner's rule presented in Section 3.2, the accumulation of damage can be integrated by means of a

(a)

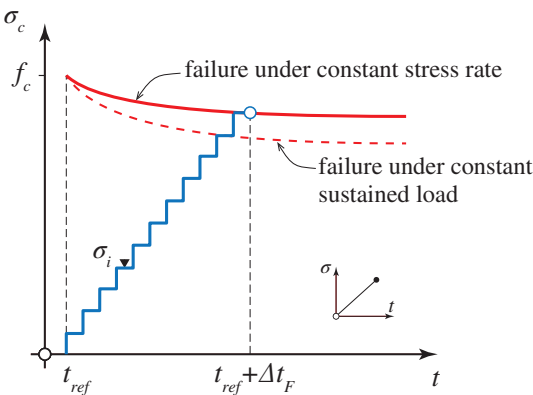

discretization of the loading history in time steps. Figure 8 shows for instance the case of a constant stress rate without and with an initial stress level $\left(\sigma_{\text {perm }}\right.$, refer to Figure $8 \mathrm{a}$ and $\mathrm{b}$, respectively). According to the Palmgren-Miner's rule, the first load steps generate low or no damage in the material. The stress level at failure for a given duration of the loading pattern is consequently higher than the one corresponding to a sustained loading pattern (refer to the solid and dashed lines in Figure 8). When an initial stress level is applied (Figure 8b), the first load steps generate more material damage and the failure stress is consequently closer to that of a constant sustained loading.

The results for these loading cases are investigated in Figures $9 \mathrm{a}, \mathrm{b}$ (case without rapid preloading and with a rapid preloading $\sigma_{\text {perm }}=0.5 \cdot f_{c}$ ), comparing the numerical predictions of the mechanical model from Tasevski et al. ${ }^{13}$ (solid lines) and the integration of Equation (13) by means of the PalmgrenMiner's rule (dashed lines). The results show fine agreement for the different regimes: when the strength decays (damage governing, higher strain rates) and when the strength increases (continued cement hydration governing, lower strain rates). Values above one are also possible for significant strength increase due to continued cement hydration (typically associated to rather low strain rates). A comparison to the test results on variable stress rates from Tasevski et al. ${ }^{13}$ (with and without rapid preloading) is also plotted in Figure $9 \mathrm{c}, \mathrm{d}$, showing sound agreement for the different cases investigated. It can be noted that the results of the model are in good agreement with the test results even for very low times of application of the load, despite the fact that the creep model used ${ }^{13}$ (fib's MC2010) has not been calibrated to precisely describe these cases.

\subsection{Application of a rapid additional loading after a period of sustained load}

Another loading pattern of practical relevance corresponds to the case when additional rapid loading is applied after a period of permanent sustained loading (Figure 7c). When the levels of permanent load are high (Figure 10a-c), material damage $\left(\varepsilon_{c c, \text { in }}\right.$ in Figure $\left.10 \mathrm{~b}\right)$ develops and the strength reduces accordingly ${ }^{14}$ (see Figure 10b), with reducing strength for increasing levels of damage. At failure, the total applied stress $\left(\sigma_{t o t}\right.$, comprising the effect of permanent and

(b)

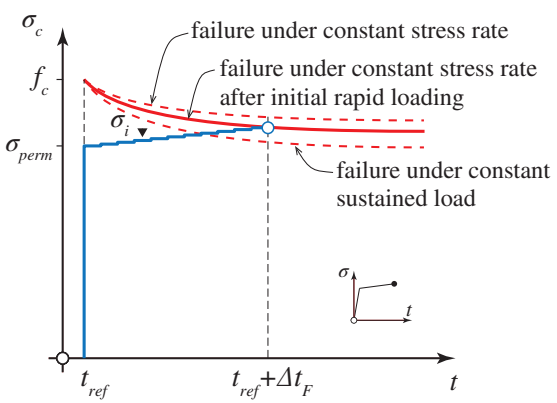

FIGURE 8 Example of a numerical discretization scheme for the Palmgren-Miner's rule for loading case of a constant stress rate: (a) no initial preload; 
(a)

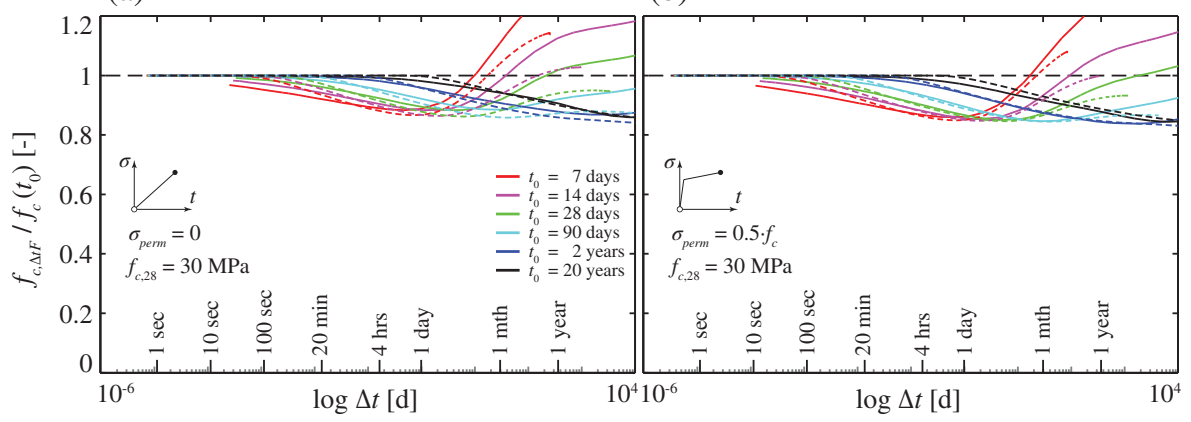

(c)

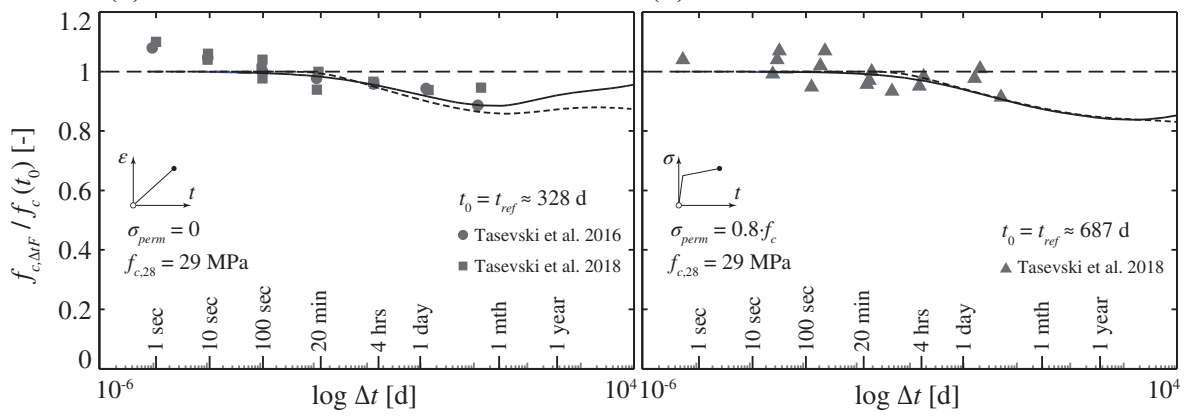

FIGURE 9 Comparison of the theoretical model ${ }^{13}$ (solid lines) and the analytical approach based on the Palmgren-Miner's rule (dashed lines) for constant stress rate with (a) no preload and (b) a preload of $\sigma_{\text {perm }}=0.5 \cdot f_{c}$; comparison to test results from Tasevski et al. ${ }^{13}$ for: (c) no preload and (d) a preload of $\sigma_{\text {perm }}=0.8 \cdot f_{c} .(s=0.25)$

variable actions) equals the compressive strength accounting for the detrimental effect of sustained loading and the beneficial effect of continued cement hydration.

For practical purposes, two situations may be relevant with respect to this loading pattern:

- Application of the variable action after a permanent stress level $\left(\sigma_{\text {perm }}\right.$ in Figure 10a) above the threshold of failure under sustained load. In this case (point A in Figure 10a), large material damage occurs associated to reductions of the material strength (resulting in $\sigma_{t o t}<f_{c}\left(t_{0}+\Delta t_{1}\right)$, see Figure 10b). In any case, if the permanent action were applied for a sufficiently long period of time, a delayed failure of the material would occur even without the application of the variable action (point B in Figure 10a,c).

- Application of the variable action after a permanent stress level ( $\sigma_{\text {perm }}$ in Figure 10d) below the threshold of failure under sustained load. In this case, if the stress level is sufficiently low, the material will suffer no (or very limited) damage and no strength reduction will be apparent $\left(\sigma_{\text {tot }}=f_{c}\left(t_{0}+\Delta t_{1}\right)\right.$, point $\mathrm{D}$ in Figure 10f). However, in some cases (for permanent stress levels close to the sustained load strength, Figure 10e), a certain material damage can occur and this can potentially lead to a reduction of the material strength when the variable action is applied (point $\mathrm{C}$ in Figure 10d,e). In this case, as the continued cement hydration eventually compensates for the material damage due to the sustained loading, a minimum value to the strength can be found (represented as point $\mathrm{C}^{\prime}$ in Figure 10d).
For the former situation (Figure 10a-c), the envelopes of the reduction of strength (points A) for a constant level of permanent stress $\left(\sigma_{\text {perm }}\right)$ are plotted in Figure 11a. The case corresponding to the permanent stress level equal to the sustained load strength is represented by the green curve, while cases with higher levels of permanent load are plotted as gray curves. The dark gray area in the top right corner of Figure $11 \mathrm{~b}$ denotes thus the area where a failure under permanent load is possible even if no variable actions were applied.

It is interesting to note that similar shapes of the curves (almost linear) and strength reductions are found for other times of application of the permanent load $\left(t_{0}\right.$, refer to the red and blue dashed curves in Figure 11b).

For the case of permanent stress levels below the sustained load strength of concrete (no delayed failure under only permanent load), the solid curves in Figure $11 \mathrm{~b}$ represent the envelopes of minimum material resistance after application of the variable action (points $\mathrm{C}^{\prime}$ in Figure 10d). The shape of these curves can again be reasonably approximated by a linear segment, defining the region where a reduction on the concrete strength can potentially happen due to the damage developed during the application of the permanent stress level (refer to the area shaded in light gray in Figure 11b). It is interesting to note that for ratios $\sigma_{\text {perm }} /$ $\sigma_{\text {tot }}<0.75$ no strength reduction is to be accounted for. Above this threshold, safe design can be performed by considering a linear reduction (up to $20 \%$ ) of the uniaxial compressive strength. This can be considered in the format of a design expression as follows: 
(a)

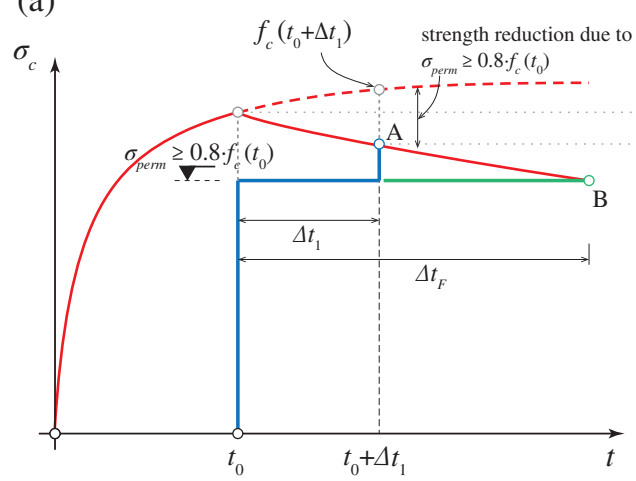

(d)

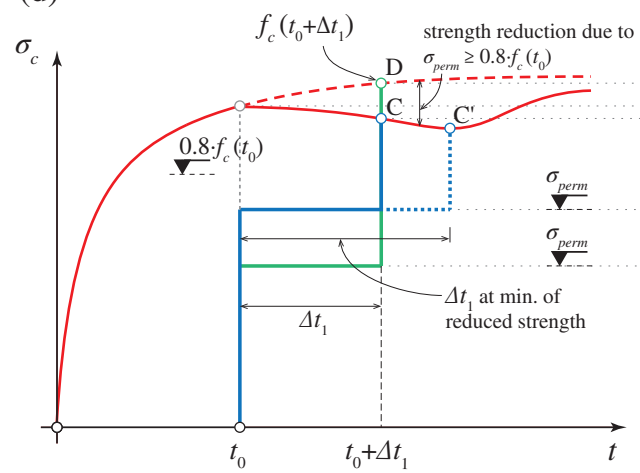

(b)

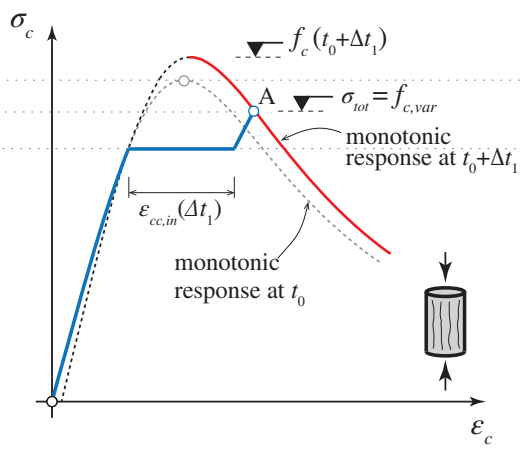

(e)

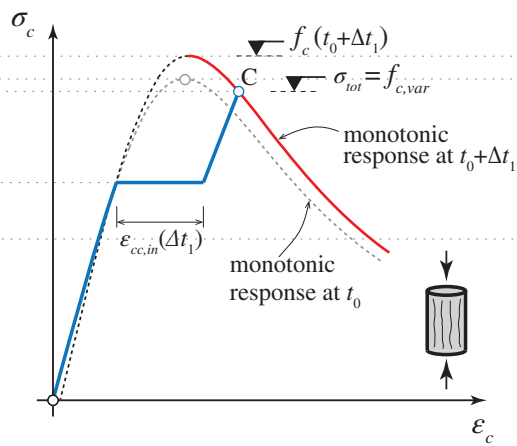

(c)

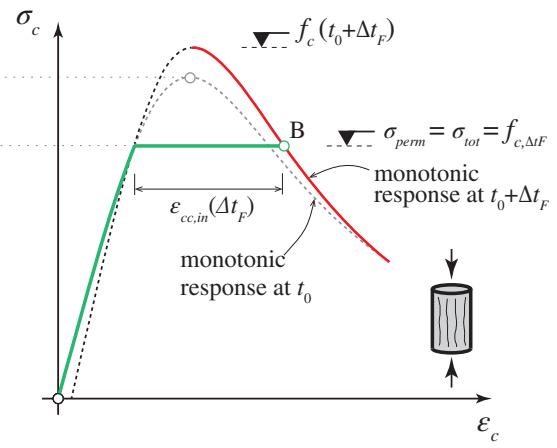

(f)

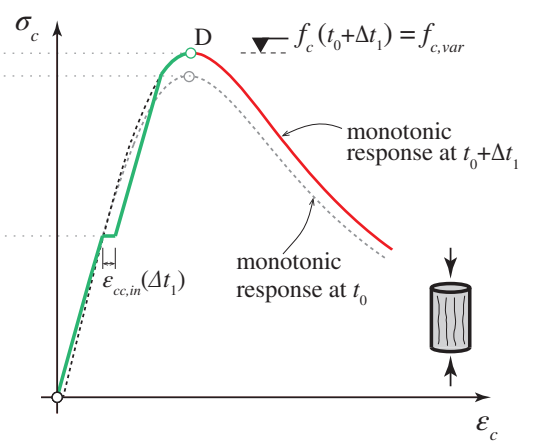

FIGURE 10 Response of concrete for the application of a variable action after a period of sustained load: (a) loading patterns for $\sigma_{\text {perm }}$ levels above the sustained load strength; (b-c) corresponding stress-strain responses; (d) loading patterns for $\sigma_{\text {perm }}$ levels below the sustained load strength; (e-f) corresponding stress-strain responses

(a)

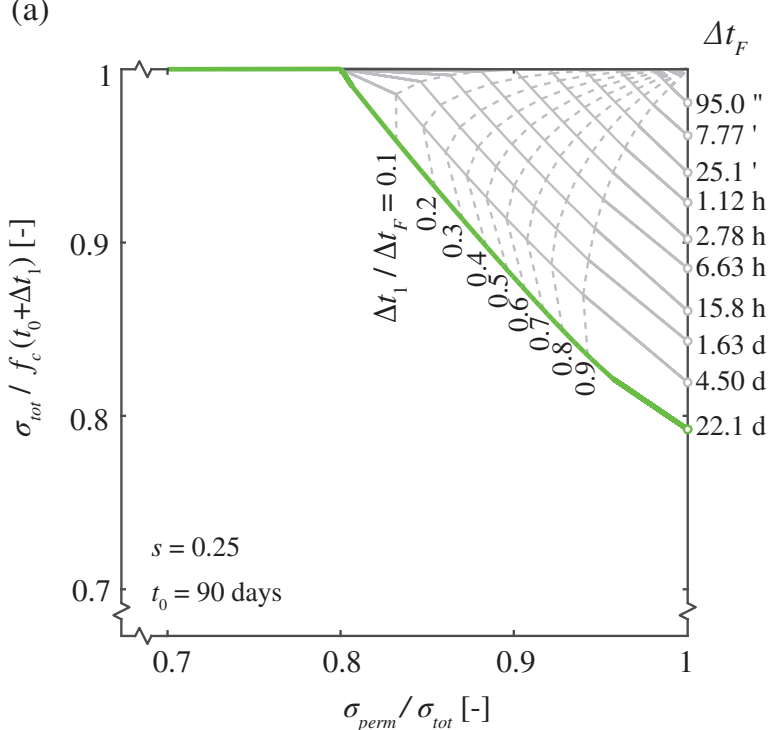

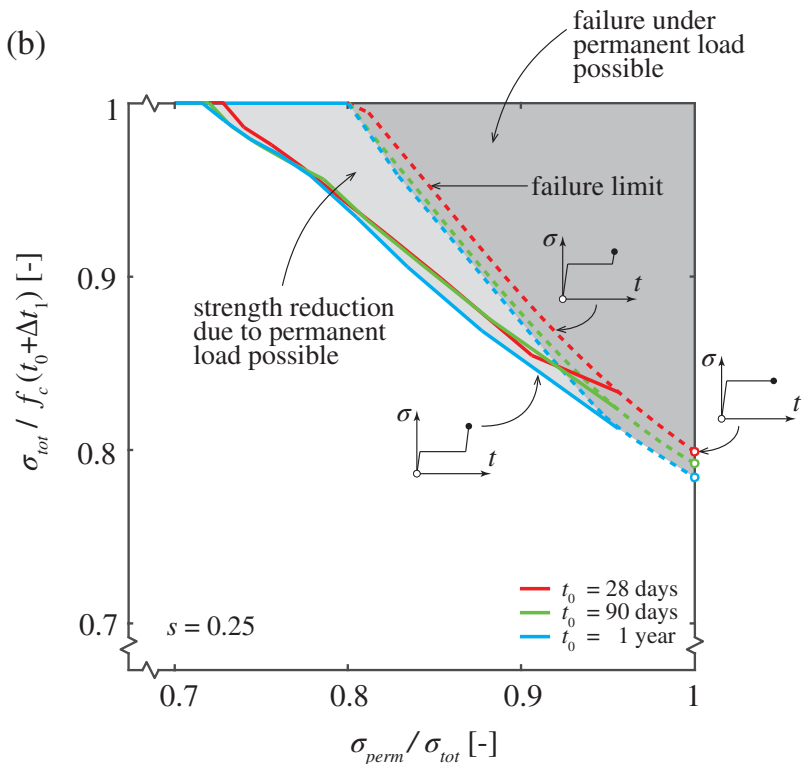

FIGURE 11 Response of concrete for the application of variable action after a period of sustained load: (a) envelopes of the reduction of strength for $\sigma_{\text {perm }}$ level above the sustained load strength; (b) areas of danger of strength reduction with and without failure danger

$$
\begin{aligned}
& \frac{\sigma_{\text {tot }}}{f_{c}\left(t_{0}+\Delta t_{1}\right)}=1.0 \text { if } \frac{\sigma_{\text {perm }}}{\sigma_{\text {tot }}} \leq 0.75 \\
& \frac{\sigma_{\text {tot }}}{f_{c}\left(t_{0}+\Delta t_{1}\right)}=1.6-0.8 \frac{\sigma_{\text {perm }}}{\sigma_{\text {tot }}} \text { if } \frac{\sigma_{\text {perm }}}{\sigma_{\text {tot }}}>0.75 .
\end{aligned}
$$

It can be noted that for total levels of stress $\sigma_{t o t} \leq 0.75$ $\cdot f_{c}\left(t_{0}+\Delta t_{1}\right)$, there is no strength reduction.

\section{I PRACTICAL DESIGN CONSIDERATIONS}

\section{1 | Implications for codes of practice}

In codes of practice, the design compressive strength of concrete is used in a number of situations such as (i) the 
resistance of axially-loaded members (e.g., columns), (ii) the compression zone due to bending, (iii) the compression field due to shear in webs of girders and beams, (iv) the strut resistance when designing using strut-and-tie models or stress fields and (v) partially loaded areas (e.g., introduction of bearing or prestressing forces). For all these cases, design equations used in codes of practice have been validated and calibrated on the basis of laboratory tests. Since these tests are usually conducted in a period varying between approximately $20 \mathrm{~min}$ and some hours, it can be stated that the structural design formulas for verification at ultimate limit state already partially account in an implicit manner for the detrimental influence of low stress or strain rates. Figure 12 shows for instance that for typical test durations and typical specimen ages, it can be assumed a compressive concrete strength decrease between $4 \%-8 \%$ compared to a material test duration of approximately 2 min (according to ISO 1920-4:2005 ${ }^{10}$ ). For this reason, the strength ratio at failure previously discussed $\left(\sigma_{t o t} l f_{c}\left(t_{0}+\Delta t_{1}\right)\right)$ may be corrected by increasing it by approximately $6 \%$ when formulas for design of structural elements are used. Thus, in the previous Equation (17), this effect can be accounted for by shifting the curve in the following manner:

$$
\begin{aligned}
& \frac{\sigma_{\text {tot }}}{f_{c}\left(t_{0}+\Delta t_{1}\right)}=1.0 \text { if } \frac{\sigma_{\text {perm }}}{\sigma_{\text {tot }}} \leq 0.85 \\
& \frac{\sigma_{\text {tot }}}{f_{c}\left(t_{0}+\Delta t_{1}\right)}=1.85-\frac{\sigma_{\text {perm }}}{\sigma_{\text {tot }}} \text { if } \frac{\sigma_{\text {perm }}}{\sigma_{\text {tot }}}>0.85,
\end{aligned}
$$

where design values for the stress and material strength shall be considered (Figure 1b). As a consequence, for the case $\sigma_{\text {perm }} / \sigma_{\text {tot }}=1$, the limit stress value shifts from 0.80 (Equation (17)) to 0.85 (Equation (18)). It can also be noted that, for practical purposes, the stresses indicated in Equation (18) are normally replaced by a generalized stress (internal forces).

(a)

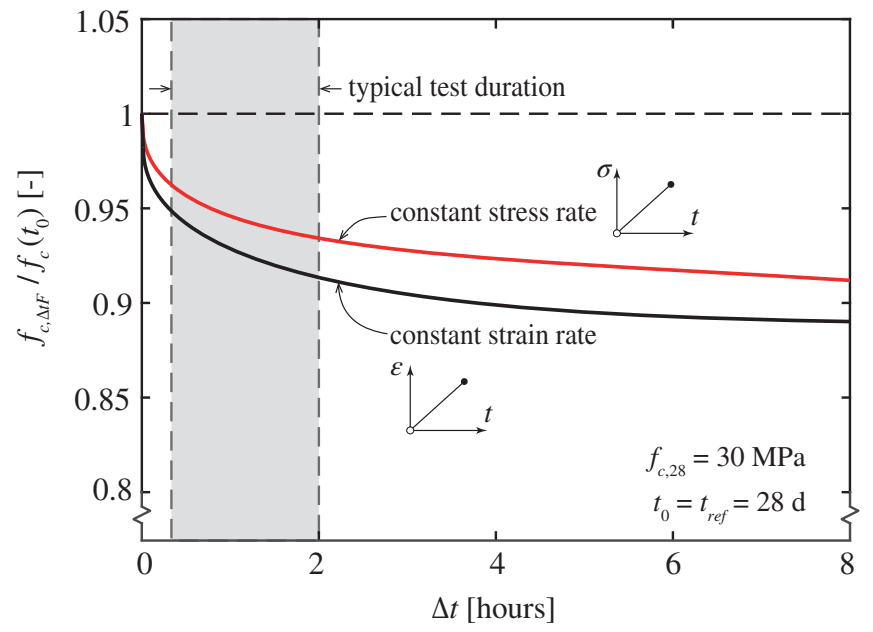

\section{2 | Design versus assessment}

As already introduced, for design of new structures, codes of practice usually assume that the detrimental effect of sustained loading is compensated by the strength increase due to continued cement hydration. This fact is investigated in Figure 13 for the most critical loading case $\left(\sigma_{p e r m} / \sigma_{t o t}=1\right)$ and with reference to different types of cement (defined by the parameter $s$ characterizing the rheology of cement hydration and thus the increase of concrete strength with time ${ }^{37}$ ). The results are calculated on the basis of the refined rheological approach by Tasevski et al. ${ }^{13}$ and assuming Equation (10) for calculation of the continued cement hydration (refer to black curves in the diagrams for the material compressive strength for rapid loading). In the figures, several cases are presented corresponding to the application of a sustained load at different ages. It can be observed that, for a given $t_{0}$, the strength decreases as the time of application of the sustained load increases, reaching an envelope curve (red curves in Figure 13) at approximately $80 \%$ of the rapid loading strength.

It can be noted that the assumption that the detrimental effect of the sustained load on the compressive strength is compensated by the continued cement hydration is valid only when the time of load application $t_{0}$ is sufficiently large (refer to the construction sequence in Figure 1b). With this respect, the areas shaded in light gray in Figure 13 refer to the period when the sustained loading effect is not fully compensated by the continued cement hydration. In addition, the time when the concrete strength is not fully compensated depends significantly on the value of parameter $s$. For instance, considering a $t_{\text {ref }}=28$ days (see Figure 13), the full compensation of the strength occurs after 4 months for $s=0.35$ (low early strength class concrete) and 2 years for $s=0.25$ (ordinary early strength class concrete). For the case of $s=0.15$ (very high-early strength class concrete),

(b)

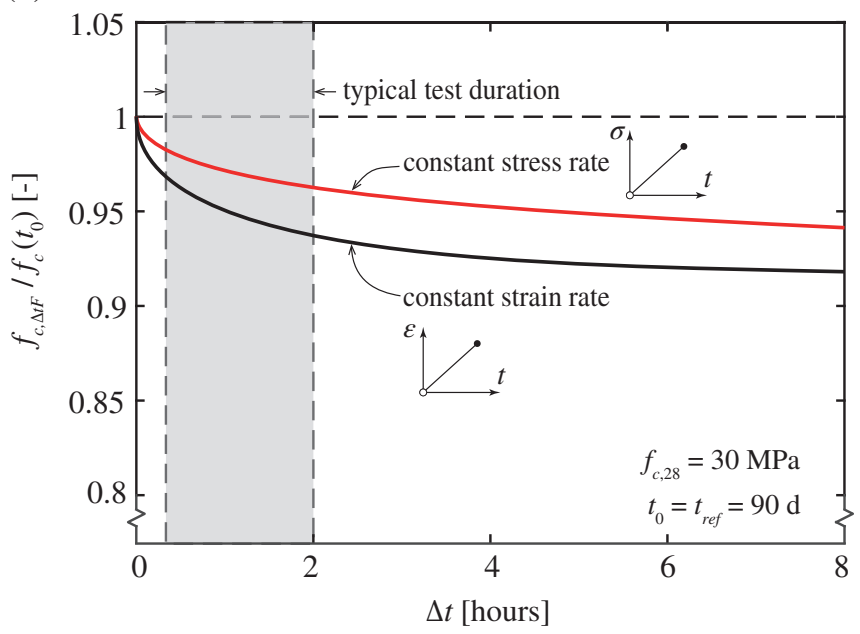

FIGURE 12 Influence of test duration on the compressive strength of concrete for constant stress and strain rates for: (a) $t_{0}=28$ days; (b) $t_{0}=90$ days (calculated according to the approach of Tasevski et al. ${ }^{13}$ ) 
(a)

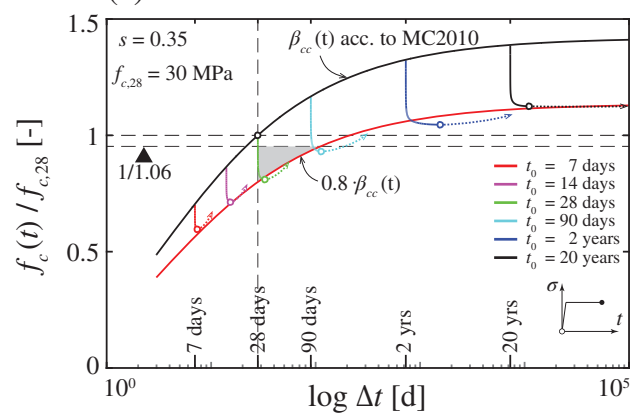

(b)

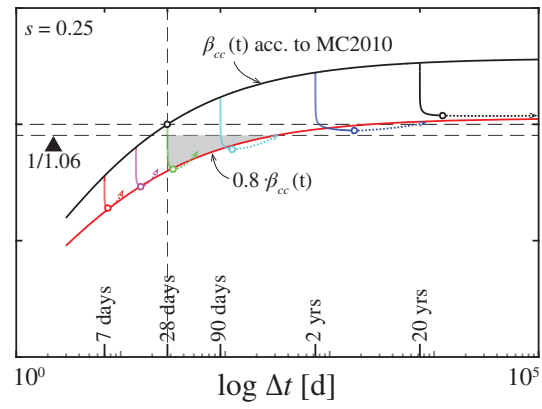

(c)

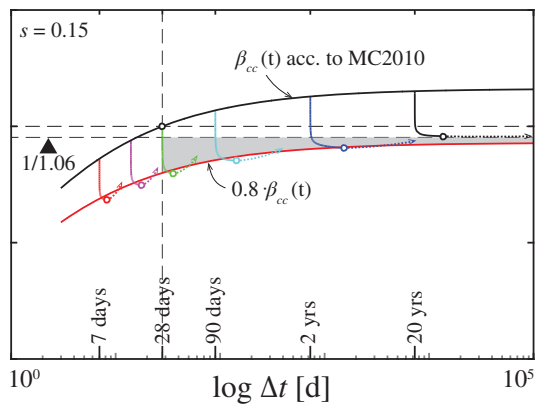

FIGURE 13 Influence of the age of loading on the delayed failure under sustained load $\left(f_{c, 28}=30 \mathrm{MPa}\right)$ : (a) $s=0.35$ (low early strength class concrete); (b) $s=0.25$ (ordinary early strength class concrete); and (c) $s=0.15$ (high-early strength class concrete)

the continued cement hydration does not even appear to fully compensate for the effects of sustained loading.

With this respect, and as previously discussed, it shall be noted that for design of structural members (columns, bending, shear in webs...) the detrimental effect of sustained loading is already partially accounted for in the design equations. This implies that, for design of structural members, the period where the continued cement hydration does not fully compensate for the sustained loading effect can in fact be assumed shorter than for the material response. This can be seen in Figure 13, where the corrected ratio between the failure under sustained load strength (1/1.06 discussed in Section 4.1) is also plotted.

For assessment of existing structures, the approach to be followed is very different to that for design. The concrete strength is in this case usually updated by means for instance of core samples extracted from the actual structure at a time $t_{\text {ref }}$ much larger than 28 days (normally some years or decades after construction). Consequently, the concrete strength increase due to continued cement hydration can be reasonably neglected and, if the sustained loading is governing $\left(\sigma_{\text {perm }} \approx \sigma_{\text {tot }}\right)$, then a conservative value $\sigma_{\text {too }} l f_{c}\left(t_{0}+\Delta t_{1}\right)=0.85(\approx 0.8 \cdot 1.06)$ should be assumed. This assumption is obviously safe and when variable (rapid) actions may have significant relevance, a more refined estimate of the strength can be obtained by means of Equations (17) and (18) (material and structural levels, respectively).

For more complex loading patterns or when more accurate estimates of the strength reduction shall be obtained (both for design and for assessment), the general approaches described in this paper (using the Palmgren-Miner rule or the general rheological approach by Tasevski et al. ${ }^{13}$ ) can for instance be used.

\subsection{Influence of time of application of variable loads on the strength of concrete}

The case of application of a variable action after a period of sustained load was investigated in Section 3.4 by considering the variable action as instantaneous. However, this might not be the case in many design situations, where the variable actions might be applied during some minutes, hours or even days (refer to point $\mathrm{E}$ in Figure 14a).

In a general manner, the influence of the duration of the application of the variable load on the concrete strength can be addressed by using the general procedures presented in this paper. Figure 14b,c show for instance the results calculated by using the refined model of Tasevski et al. ${ }^{13}$ with reference to two values of parameter $s(0.25$ and 0.15 , respectively, values for $s=0.35$ being almost identical to those of $s=0.25$ ). In those figures, the factor increasing the strength by $6 \%$ has already been considered, in order to be consistent with the application of these results to design formulas (referring normally to generalized stresses or internal forces). The results show that a reduction on the strength can already be noted for relatively low times of application of the variable load and that it can clearly be appreciated for durations of the variable load of some days. The ratio $\sigma_{\text {perm }} / \sigma_{\text {tot }}$ also plays a significant role, by reducing notably the strength for ratios $\sigma_{p e r m} / \sigma_{t o t}$ above 0.6 .

\section{5 | CONCLUSIONS}

This paper investigates on the reduction of the strength of concrete when it is subjected to high levels of sustained stress and to different loading patterns. A simplified analytical approach is proposed based on the general mechanical model by Tasevski et al. ${ }^{13}$ The main conclusions of this paper are:

1. The phenomenon of concrete creep shall be accounted for both for Serviceability Limit States (SLS) and Ultimate Limit States (ULS). Even if at SLS the ratio between the applied stresses and the material strength is moderate, at ULS this ratio might be high accounting for the characteristic values of actions and material strengths and for the safety coefficients. In this latter case, material damage may develop (characterized by microcrack progression and coalescence) and lead to failures under sustained load. 
(a)

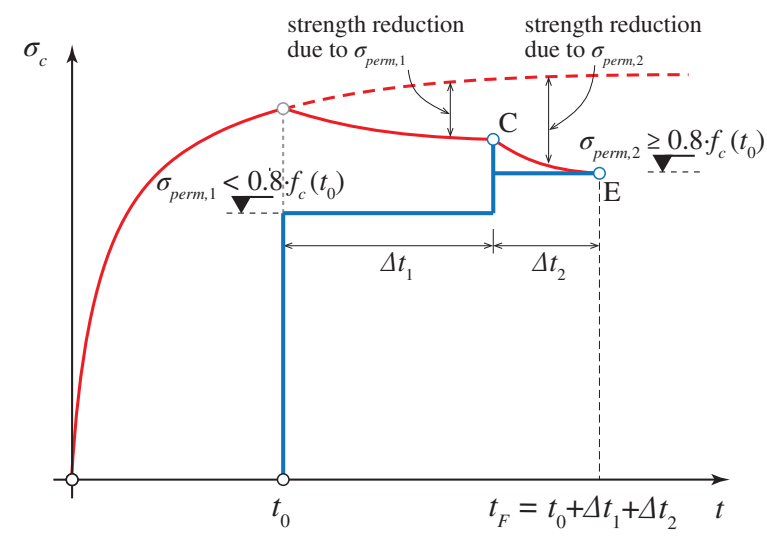

(b)

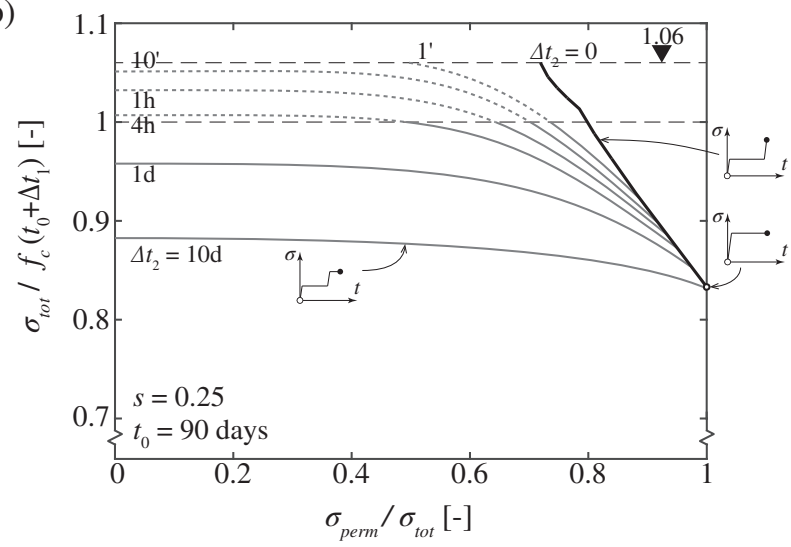

(c)

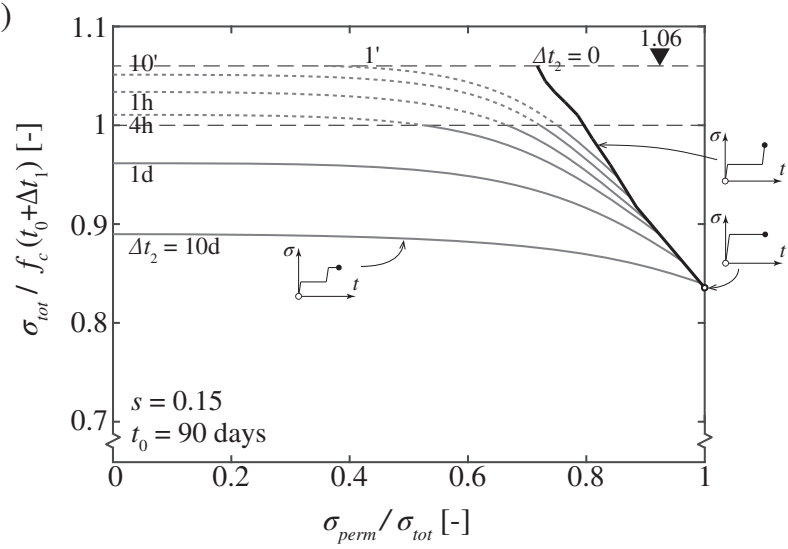

FIGURE 14 Influence of the duration of the application of the variable load: (a) load pattern; (b and c) strength reductions (for structural design) as a function of the duration of the variable action

2. The development of inelastic strains associated to material damage due to the application of high levels of stress is potentially detrimental for the strength of a member, unless they can be compensated by the increase of strength due to the continued cement hydration. This material damage is associated to the development of nonlinear creep strains which however have a potentially favorable effect for the structural strength, allowing for stress redistributions between more and less stressed regions. This latter phenomenon is particularly beneficial and notorious for compression regions in bending (with a strain gradient) or for reinforced concrete columns, where the longitudinal reinforcement can be additionally activated.

3. Simple expressions can be derived to characterize the failure load of concrete under sustained stress. Combining these expressions with the Palmgren-Miner's rule provides a practical manner to account for damage accumulation and to estimate the failure load and time. When compared to test results, both a detailed material-damage approach and the simplified Palmgren-Miner's rule yield fine and consistent results for stress and strain rate loading patterns.

4. The analyses presented in this paper confirm that the beneficial effect of continued cement hydration usually compensates for the detrimental effect of sustained loading. This holds true provided that the concrete strength is determined at 28 days and the ULS occurs after a sufficiently long period of time. In case the concrete strength is determined later than 28 days (particularly relevant for assessment of existing structures), the reduction of concrete strength accounting for long-term and high-sustained loading is justified.

5. When concrete is loaded some weeks after casting, the results of this paper confirm that failures under sustained loading typically occur after some hours or days. However, when a concrete is loaded at very high age (some years or decades), failures may potentially occur after a longer period of time.

6. For a given level of total stress, a combination of permanent actions and a rapid variable action is less detrimental for the concrete compressive strength than a full permanent action. This phenomenon can be described by simple, code-like expressions resulting in a linear interpolation between the response of a member failing under constant sustained load and the case where permanent load effects can be neglected. Also, for cases where the variable action is maintained over a period of time, a similar approach can be followed (associated to larger strength reductions than rapid applications of the variable loads).

\section{ACKNOWLEDGMENTS}

The authors acknowledge the financial support from the Swiss Federal Roads Office (FEDRO), project No. AGB2013-001.

\section{NOTATION}

Variables

$f_{c} \quad$ uniaxial compressive strength of concrete [MPa]

$f_{c, \text { tref }}$ reference compressive strength obtained at a strain rate of $0.02 \% \circ \cdot \mathrm{s}^{-1}$ and at an age $t_{\text {ref }}[\mathrm{MPa}]$

$f_{c, 28} \quad$ reference compressive strength at an age $t_{r e f}=28$ days [MPa]

$f_{c, \Delta t F} \quad$ compressive stress at failure under sustained load or stress/strain rate [MPa] 
$f_{c, v a r} \quad$ compressive stress at failure under variable action after a permanent load $\sigma_{\text {perm }}[\mathrm{MPa}]$

$k_{1}, k_{2} \quad$ constant

$k_{t} \quad$ strength reduction factor of concrete accounting for sustained load action

$t \quad$ time

$t_{0} \quad$ concrete age at loading [days]

$t_{r e f} \quad$ concrete age at reference strength testing [days]

$\Delta t \quad$ time under sustained stress for a constant stress level test or time after beginning of a strain or stress rate test (in the case of rapid initial loading, time after the initial loading ramp)

$\Delta t_{F} \quad$ time under sustained stress required to attain failure

$\alpha$ parameter governing the shape of tertiary creep strain development curve

$\beta_{c c}$

$\gamma$

$\dot{\varepsilon}$

$\varepsilon_{c}$

$\varepsilon_{c 0}$

$\varepsilon_{c c}$

$\varepsilon_{c s}$

$\lambda$

$\eta, \eta_{\tau}$

$\sigma_{c}$

$\sigma_{\text {perm }}$

$\sigma_{\text {tot }}$

$\varphi$

av

$c$

$c c$

$c c, 1$

$c c, 2$

$c c, 3$

cs

in

lin

$n l$

F

perm

ref

tot

$\tau$

var

\section{ORCID}

Darko Tasevski (1D https://orcid.org/0000-0003-4610-6639 Miguel Fernández Ruiz (1D https://orcid.org/0000-0001-67208162

\section{REFERENCES}

1. Smeaton JA. Narrative of the building and a description of construction of the Eddystone lighthouse with stone. London, UK: H. Hughs, 1791; p. 198.

2. Swiss Society of Engineers and Architects (SIA). "Provisional standards for the design, execution and inspection of structures in reinforced concrete." (in German: "Provisorische Normen für Projektierung, Ausführung und Kontrolle von Bauten in armiertem Beton."). Zürich: V. F. Lohbauer; 1903; p. 8.

3. Mörsch E. Reinforced concrete construction, theory and application. (in German: "Der Eisenbetonbau, seine Theorie und Anwendung"). 4th ed. Stuttgart: Verlag von Konrad Wittwer, 1912; p. 710.

4. Kaltakci MY, Arslan MH, Korkmaz HH, Ozturk M. An investigation on failed or damaged reinforced concrete structures under their own-weight in Turkey. Eng Fail Anal. 2007;14:962-969.

5. Hamed E. Modelling of creep in continuous RC beams under high levels of sustained loading. Mech Time Dependent Mater. 2014;18(3):589-609.

6. Shank JR. Plastic flow of concrete at high overload. ACI J. 1949;45(2): 493-498.

7. Rüsch, H., (1956). "Experimental determination of the effect of the duration of loading on the resistance and deflection." (in German: "Versuche zur Bestimmung des Einflusses der Zeit auf Festigkeit und Verformung."). Report. IABSE congress report, 5, 237-244.

8. Rüsch $\mathrm{H}$. Researches toward a general flexural theory for structural concrete. ACI J. 1960;57(1):1-28.

9. Rüsch, H., Sell, R., Rasch, C., Grasser, E., Hummel, A., Wesche, K. and Flatten, H., (1968). "Strength and deformation of plain concrete under sustained loading." (in German: "Festigkeit und Verformung von unbewehrtem Beton unter konstanter Dauerlast."). Report. Deutscher Ausschuss für Stahlbeton, Vol. 198, Ed. Berlin: Wilhelm Ernst \& Sohn, 86.

10. ISO 1920-4:2005. Testing of concrete-part 4: Strength of hardened concrete. Geneva, Switzerland: International Organization for Standardization, 2005; p. 27.

11. Stöckl S. Strength of concrete under uniaxial sustained loading. ACI Special Publ. 1972;34:313-326.

12. Fédération internationale du béton. fib Bulletin 70: Code-type models for concrete behaviour: Background of MC2010. Technical report, Lausanne, Switzerland, ISBN 2-88394-110-6, 2013, p. 196.

13. Tasevski D, Fernández Ruiz M, Muttoni A. Compressive strength and deformation capacity of concrete under sustained loading and low stress rates. J Adv Concrete Technol. 2018;16(8):396-415.

14. Fernández Ruiz M, Muttoni A, Gambarova PG. Relationship between nonlinear creep and cracking of concrete under uniaxial compression. J Adv Concrete Technol. 2007;5(3):383-393.

15. Schlappal T, Schweigler M, Gmainer S, Peyerl M, Pichler B. Creep and cracking of concrete hinges: Insight from centric and eccentric compression experiments. Mater Struct. 2017;50(244):1-16.

16. Shah SP, Chandra S. Fracture of concrete subjected to cyclic and sustained loading. ACI J Proc. 1970;67(10):816-827.

17. Awad, M.E. and Hilsdorf, H.K., (1971). "Strength and Deformation Characteristics of Plain Concrete Subjected to High Repeated and Sustained Loads." Report. Structural Research Series, No. 372, University of Illinois, 266.

18. Diaz, S.I. and Hilsdorf, H.K., (1971). "Fracture Mechanics of Concrete under Static, Sustained and Repeated Compressive Loads." Report. Structural Research Series, No. 382, University of Illinois, 198.

19. Wittmann FH, Zaitsev J. Behaviour of hardened cement paste and concrete under sustained load. Proceedings of society of materials science conference on the mechanical behavior of materials. Kyoto, Japan: Society of Material Science, Volume 4, 1972; p. 84-95.

20. Coutinho SA. A contribution to the mechanism of concrete creep. Mater Struct. 1977;10(55):3-16.

21. Fouré, B., (1985). "Long-term strength of concrete under sustained loading." (in French: "Résistance potentielle à long terme du béton soumis à une contrainte soutenue."). Report. Annales de l'Institut Technique du Bâtiment et des Travaux Publics, No. 431, Paris, France, 45-64.

22. Smadi MM, Slate FO, Nilson AH. High-, medium-, and low-strength concretes subject to sustained overloads - strains, strengths, and failure mechanisms. ACI J. 1985;82(5):657-664.

23. Ngab AS, Nilson AH, Slate FO. Shrinkage and creep of high strength concrete. ACI J. 1981;78(4):255-261. 
24. Smadi, M.M. Time-dependent behavior of high-strength concrete under high sustained compressive stresses [doctoral thesis]. Cornell University; 1983, 297.

25. Han N, Walraven JC. Properties of high-strength concrete subjected to uniaxial loading. ACI Special Publ. 1994;149:269-288.

26. Iravani S, MacGregor JG. Sustained load strength and short-term strain behavior of high-strength concrete. ACI Mater J. 1998;95(5):636-647.

27. Müller HS, Burkart I, Budelmann H, et al. Time-dependent behaviour of ultra high performance concrete (UHPC). Proceedings of the 3rd international fib congress, Washington D.C. 29 May-2 June 2010, Chicago, Illinois: Precast Prestressed Concrete Institute (PCI), 2010; p. 15.

28. Domone PL. Uniaxial tensile creep and failure of concrete. Mag Concr Res. 1974;26(88):144-152.

29. Reinhardt, H.-W. and Cornelissen, H.A.W., (1985) "Sustained Tensile Tests of Concrete" (in German: "Zeitstandzugversuche an Beton."). Report. Baustoffe '85, Karlhans Wesche gewidmet, Ed. Bauverlag Wiesbaden, 162-167.

30. Reinhardt H-W, Rinder T. Tensile creep of high-strength concrete. J Adv Concrete Technol. 2006;4(2):277-283.

31. El-Kashif KF, Maekawa K. Time-dependent nonlinearity of compression softening in concrete. J Adv Concrete Technol. 2004;2(2):233-247.

32. Fischer I, Pichler B, Lach E, Terner C, Barraud E, Britz F. Compressive strength of cement paste as a function of loading rate: Experiments and engineering mechanics analysis. Cem Concr Res. 2014;58:186-200.

33. Berthollet A, Georgin J-F, Reynouard J-M. Tertiary creep of concrete in tension. (in French: "Fluage tertiaire du béton en traction."). Revue Française de Génie Civil. 2004;8(2-3):235-260.

34. Rossi P, Tailhan J-L, Le Maou F. Creep strain versus residual strain of a concrete loaded under various levels of compressive stress. Cem Concr Res. 2013;51:32-37.

35. Wittmann, F.H. and Zaitsev, J., (1974). Deformation and Rupture Process of Porous Construction Materials under Short-term and Sustained Load. (in German: "Verformung und Bruchvorgang poröser Baustoffe bei kurzzeitiger Belastung und Dauerlast."). Report. Deutscher Ausschuss für Stahlbeton, Vol. 232, Ed. Berlin: Wilhelm Ernst \& Sohn, 67-145.

36. Claisse $P$, Dean C. Compressive strength of concrete after early loading. Proc Inst Civil Eng-Construct Mater. 2013;166(3):152-157.

37. Fédération internationale du béton. fib Model Code for Concrete Structures 2010. Germany: Ernst \& Sohn, 2013;p. 434.

38. Eurocode 2. Design of Concrete Structures - General Rules and Rules for Buildings, EN 1992-1-1. Brussels, Belgium: CEN European Committee for Standardization, 2004:225.

39. Hellesland J, Green R. A stress and time dependent strength law for concrete. Cem Concr Res. 1972;2:261-275.

40. Carol I, Murcia J. A model for the non-linear time-dependent behaviour of concrete in compression based on a Maxwell chain with exponential algorithm. Mater Struct. 1989;22(3):176-184.

41. Mazzotti C, Savoia M. Nonlinear creep, Poisson's ratio, and creep-damage interaction of concrete in compression. ACI Mater J. 2002;99(5):450-457.

42. Bockhold J, Stangenberg F. Modelling of nonlinear creep of concrete (in German: Modellierung des nichtlinearen Kriechens von Beton."). Betonund Stahlbetonbau. 2004;99(3):209-216.

43. Challamel N, Lanos C, Casandjian C. Creep damage modelling for quasibrittle materials. Eur J Mech A/Solids. 2005;24(4):593-613.

44. Zhou, F.P. Time-dependent crack growth and fracture in concrete [doctoral thesis]. LTH, Lund University; 1992, 132.

45. Van Zijl GPAG, de Borst R, Rots JG. The role of crack rate dependence in the long-term behaviour of cementitious materials. Int J Solid Struct. 2001; 38(30):5063-5079.

46. Barpi F, Valente S. Creep and fracture in concrete: A fractional order rate approach. Eng Fract Mech. 2002;70(5):611-623.

47. Di Luzio G. Numerical model for time-dependent fracturing of concrete. ASCE J Eng Mech. 2009;135(7):632-640.

48. Karsan AI, Jirsa JO. Behavior of concrete under compressive loadings. ASCE J Struct Div. 1969;95:2535-2563.

49. Zanuy C, Albajar L, de la Fuente P. Sectional analysis of concrete structures under fatigue loading. ACI Struct J. 2009;106(5):667-677.

50. Comité Européen du Béton (CEB), "Fundamentals for the design of concrete structures in uniaxial stress states." (in French : "Principes de calcul du béton armé sous des états de contraints monoaxiaux.") CEB Bulletin d'information No. 36, Luxembourg, 1962, p. 112.

51. Mattock AH, Kriz LB, Hognestad E. Rectangular concrete stress distribution in ultimate strength design. ACI J Proc. 1961;57(2):875-928.
52. Fernández Ruiz, M. "Nonlinear analysis of the structural effects of the delayed strains of steel and concrete." (in Spanish: "Evaluación no lineal de los efectos estructurales producidos por las deformaciones diferidas del hormigón y el acero.") [doctoral thesis]. Polytechnic University of Madrid. Ed. ACHE; 2003, 175.

53. Palmgren AG. Life Length of Roller Bearings. (in German: "Die Lebensdauer von Kugellagern."). Zeitschrift des Vereins Deutscher Ingenieure. 1924;68(14):339-341.

54. Miner M. Cumulative damage in fatigue. J Appl Mech. 1945;67:159-164.

55. Oh BH. Cumulative damage theory of concrete under variable-amplitude fatigue loadings. ACI Mater J. 1991;88(1):41-48.

56. Miller KJ, Mohamed HJ, de los Rios ER. Fatigue damage accumulation above and below the fatigue limit. In: Miller KJ, de los Rios ER, editors. Report. The behaviour of short fatigue cracks, EGF Pub 1. London, UK: Mechanical Engineering Publications, 1986; p. 491-511.

57. Zhang B, Phillips DV, Wu K. Effects of loading frequency and stress reversal on fatigue life of plain concrete. Mag Concr Res. 1996;48(177):361-375.

58. Holmen JO. Fatigue of concrete by constant and variable amplitude loading. ACI Special Publ. 1982;75:71-110.

59. Hilsdorf HK, Kesler C. Fatigue strength of concrete under varying flexural stresses. ACI J Proc. 1966;63(10):1059-1076.

\section{AUTHORS' BIOGRAPHIES}

Darko Tasevski, PhD Candidate
École Polytechnique Fédérale de
Lausanne, School of Architecture,
Civil and Environmental Engineer-
ing, Station 18, CH-1015 Lausanne,
Switzerland
darko.tasevski@epfl.ch
Miguel Fernández Ruiz, PhD Senior
Lecturer, École Polytechnique Fédér-
ale de Lausanne, School of Architec-
ture, Civil and Environmental
Engineering, Station 18, CH-1015
Lausanne, Switzerland
miguel.fernandezruiz@epfl.ch
Aurelio Muttoni, PhD Professor,
École Polytechnique Fédérale de
Lausanne, School of Architecture,
Civil and Environmental Engineer-
ing, Station 18, CH-1015 Lausanne,
Switzerland
aurelio.muttoni@epfl.ch

How to cite this article: Tasevski D, Fernández Ruiz M, Muttoni A. Assessing the compressive strength of concrete under sustained actions: From refined models to simple design expressions. Structural Concrete. 2019;20:971-985. https://doi.org/10. 1002/suco.201800303 